\title{
Surgery cancellations after entering the operating room
}

\author{
Yoko Hori", Ayami Nakayama* and Atsuhiro Sakamoto*
}

\begin{abstract}
Background: Surgery cancellation results in unavailability of the operating room and loss time. We identified the frequency of and reasons for operation cancellations after patients entered the operating room and assessed the preventability of such cancellations.

Findings: A retrospective chart review of all scheduled surgical procedures proposed under general anesthesia in a period spanning 2008 to 2016 was performed, and the reasons for cancellation were assessed.

A total of 30 surgery procedures were cancelled after the patient had entered the operation room and preparation for general anesthesia had been completed. Ten of 18 cases (55.6\%) that were cancelled before general anesthesia induction could have been prevented, accounting for $36.7 \%$ of the overall cancellations. The majority of the cancellations after anesthesia were due to the patients' health status.
\end{abstract}

Conclusions: Improving the systems for checking patients' medical problems and performing preoperative evaluations can reduce the number of cancellations after the patient has entered the operating room.

Keywords: Cancellation, General anesthesia, Surgery

\section{Findings \\ Background}

Cancellations of surgery are costly and cause loss of hospital income. In addition, cancellations give a negative impression to patients. In particular, if a cancellation occurs after the patient has entered the operating room, it results in unnecessary costs and ineffective utilization of hospital resources and causes emotional distress to the patient. It is therefore necessary to reduce such cancellations as much as possible. Many studies have suggested methods for preventing cancellation of surgery due to patients' medical problems, incomplete preoperative evaluations, system reasons, and other reasons $[1,2]$. In this retrospective review of 30 cases with unexpected cancellation of surgery after the patient had entered the operating room, we analyze the indications for cancellations and offer suggestions for decreasing unexpected surgery cancellation.

\footnotetext{
*Correspondence: hori84@nms.ac.jp; ayami-takii@nms.ac.jp; no1saka@nms.ac.jp

Department of Anesthesiology, Nippon Medical School, Sendagi 1-1-5, Bunkyo-ku, Tokyo 113-8603, Japan
}

\begin{abstract}
Methods
The authors performed a retrospective chart review of all scheduled surgical procedures under general anesthesia between December 1, 2008, and April 30, 2016, at the Nippon Medical School Hospital. We selected records of any surgery that was cancelled after the patient had already entered the operating room, before or after the induction of general anesthesia. Information about the patient and the reason for cancellation were obtained from the anesthesia record system, ORSYS ${ }^{\circ}$ (Philips Electronics Japan, Tokyo), and the hospital's electronic medical records. The ethics committee of the Nippon Medical School approved this study.
\end{abstract}

\section{Results}

A total of 30 out of 51,933 surgical procedures scheduled between December 1, 2008, and April 30, 2016 were cancelled after the patient had entered the operation room and preparation for general anesthesia had been completed. The patient characteristics and American Society of Anesthesiologists physical status are shown in Table 1, and surgical specialties are shown in Table 2.

The reasons for cancellation before induction of general anesthesia are shown in Table 3. The majority of 
Table 1 Details of the patients' characteristics of those who had their surgeries cancelled

\begin{tabular}{ll}
\hline Patient characteristics & Total $(n=30)$ \\
\hline Mean age (years) & $61.5 \pm 22.1(0.25-89)$ \\
Sex (male/female) & $18 / 12$ \\
Operating room time (minutes) & $44.3 \pm 48.8(20-217)$ \\
ASA physical status & \\
1 & $3(10.0 \%)$ \\
2 & $18(60.0 \%)$ \\
3 & $7(23.3 \%)$ \\
4 & $2(6.7 \%)$ \\
Surgery cancelled before anesthesia & $18(60.0 \%)$ \\
Surgery cancelled after anesthesia & $12(40.0 \%)$ \\
\hline
\end{tabular}

Data are means, mean $\pm S D$, ranges (minimum-maximum), or number of patients.

cases were cancelled before anesthesia because of the patient's health status. The possibility of surgery cancellation being preventable in these cases is shown also in Table 3. Two of four cases of atrial fibrillation were preventable, as this was overlooked on the preoperative 12-lead electrocardiograms. In all four shock cases, the surgeon decided in surgery that the patients' hemodynamic state was too unstable due to their condition: intestinal necrosis, multiple injuries, excessive bleeding, or disseminated intravascular coagulation (DIC). An elective surgery had to be postponed as the patient had undergone percutaneous coronary intervention (PCI) 3 days earlier, which was not communicated to the surgeon beforehand. The cancellation of surgery in two hypoxemia and two fever cases was preventable, as the associated vital signs were observed on the day prior to the scheduled surgery in the general ward. A case of head injury just before entering the operation room received a prioritized head computed tomography (CT) scan prior to anesthesia. In another case, a pacemaker check could not be performed before surgery because of the lack of the appropriate medical equipment. Thus, in total, surgery cancellations could have been

Table 2 Operations cancelled by specialism

\begin{tabular}{ll}
\hline Operations cancelled by specialism & Total $(n=30)$ \\
\hline Orthopedic surgery & $11(36.7 \%)$ \\
General surgery & $5(16.7 \%)$ \\
Vascular surgery & $4(13.3 \%)$ \\
Pulmonary surgery & $3(13.3 \%)$ \\
Ophthalmic surgery & $3(13.3 \%)$ \\
Surgery of Critical Care Medicine Center & $2(6.7 \%)$ \\
Gynecologic surgery & $1(3.3 \%)$ \\
Electric convulsive therapy & $1(3.3 \%)$ \\
\hline
\end{tabular}

Data show number of patients (and percentage)
Table 3 Cases surgery cancelled before anesthesia and cause of cancellation.

\begin{tabular}{llll}
\hline Surgery cancellation reason & Number & Preventable & $\begin{array}{l}\text { Prediction is } \\
\text { difficult }\end{array}$ \\
\hline Patient health status & 4 & 2 & 2 \\
Atrial fibrillation & 4 & 0 & 3 \\
Shock status & 1 & 0 & 1 \\
Hypertension & 1 & 0 & 1 \\
Cardiac arrest & 1 & 1 & 0 \\
After PCl & 2 & 2 & 0 \\
Hypoxemia & 2 & 2 & 0 \\
Fever & 1 & 1 & 0 \\
Head banging & & & 0 \\
System reason & 1 & 1 & 0 \\
Necessity of pacemaker & & & 8 (44.4\%) \\
check & & & 1 \\
Patient issue & 1 & 10 (55.6\%) \\
Surgery rejection & 18 & & \\
Total &
\end{tabular}

$\overline{P C l}$ percutaneous coronary intervention

prevented in 10 (55.6\%) of 18 cases before general anesthesia, accounting for $33.3 \%$ of overall cancellations.

Cases in which surgery was cancelled after anesthesia and the causes of cancellation are shown in Table 4. A change in the patient's physical status after induction of general anesthesia, such as sudden drug-related anaphylactic shock, arrhythmias, and hypoxemia caused by atelectasis, is difficult to prevent. Regarding the outcomes after surgery cancellation, in cases of cancellation before anesthesia, 12 of 18 patients underwent the procedure at a later date. The condition of the three patients who were in shock died soon after cancellation, and one patient died within 24 days, which is a high mortality rate. In the cases of hypertension and cardiac arrest, the elective cataract surgery was not performed. In the cases

Table 4 Cases surgery cancelled after anesthesia and cause of cancellation

\begin{tabular}{ll}
\hline Surgery cancellation reason & Total $(n=12)$ \\
\hline Anaphylactic shock & 3 \\
Arrhythmias & 1 \\
Arterial fibrillation & 1 \\
CAVB & 1 \\
TdP & 1 \\
Cardiac arrest & 1 \\
Hypoxemia & 1 \\
Anemia & 3 \\
Other & 1 \\
\hline CAVB complet atioventrichar block TdP Torsades de pointes
\end{tabular}

CAVB complete atrioventricular block, TdP Torsades de pointes 
of cancellation after anesthesia, 10 of 12 patients underwent the procedure at a later date after an appropriate solution was implemented. The remaining two cases received more conservative treatment.

\section{Discussion}

Our study highlights the role of insufficient evaluation of cases in which surgery is cancelled after the patient has entered the operating room. Several studies have shown the importance of preoperative anesthetic evaluation in the prevention of surgery cancellation [1-3]. Preoperative assessment by the anesthesiologist plays an important role in minimizing patient perioperative risk and preparation before surgery [4].

A Chinese study has reported that the rate of cancellations after patients entered the operating room was $0.21 \%$ [5]. A study of cardiac surgical case cancellations in Massachusetts indicated that $0.84 \%$ of such surgeries were cancelled after the patient had entered the cardiac surgical operating room [6]. In our study, the cancellation rate was less than $0.01 \%$, which was relatively low. The probable reasons for this were as follows: there are very few day surgery cases in our hospital; all patients receiving general anesthesia should undergo a medical examination and evaluation by the anesthesiologist on the day before the operation $[7,8]$.

Our case review suggested that some of the cancellations could have been prevented or that the surgery could have been delayed before the patient entered the operating room and before anesthesia. In particular, the preoperative examinations planned by the attending surgeon should be checked, and vital signs at the ward should be confirmed by ward staff. A double-checking system could also be implemented, involving a nurse checking the essential preoperative examinations before the anesthesiologist does [9]. Requests for medical devices, such as a pacemaker, should be confirmed the day prior to surgery; not doing so constitutes a lack of communication.

Based upon our study, we propose the following preoperative evaluations. Patients' vital signs (blood pressure, heart rate, body temperature, and oxygen saturation) should be measured accurately at their ward by the ward nurse and should be checked by the anesthesiologist. A structured preoperative assessment has been reported to improve operating room efficiency and reduce surgery cancellations [10]. A standardized preoperative evaluation checklist can also reduce the number of cancellations [11]. Required preoperative examinations, such as 12-lead electrocardiogram, laboratory analysis, and chest X-ray, should be confirmed before surgery and double-checked whenever possible. The patients' medical history should be shared, and communication among the medical staff should be optimal.

Surgery cancellations after induction of general anesthesia are difficult to prevent, as the main reason for such cancellations is sudden and unexpected changes in the patient's condition, such as anaphylactic shock or arrhythmia.

There were several limitations to this study. This was a retrospective, single-facility study, and the information was obtained only from medical records. No statistical analysis was performed as the number of cancellation cases was small.

\section{Conclusion}

Improving the assessment of patients' medical problems and preoperative evaluations can reduce the number of surgery cancellations after the patient has entered the operating room.

\section{Abbreviations \\ CT: Computed tomography; DIC: Disseminated intravascular coagulation; $\mathrm{PCl}$ : Percutaneous coronary intervention}

\section{Acknowledgements}

We gratefully acknowledge the work of past and present members of our institution.

Funding

Not applicable

Authors' contributions

$\mathrm{YH}$ and $\mathrm{AN}$ conceived of the study and participated in its design and coordination. AS supported the management. All authors read and approved the final manuscript.

Competing interests

The authors declare that they have no competing interests.

Consent for publication

Not applicable

Ethics approval and consent to participate

The ethics committee of the Nippon Medical School approved this study.

Received: 6 August 2016 Accepted: 18 November 2016

Published online: 25 November 2016

\section{References}

1. Ferschl MB, Tung A, Sweitzer B, Huo D, Glick DB. Preoperative clinic visits reduce operating room cancellations and delays. Anesthesiology. 2005;103: 855-9.

2. van Klei WA, Moons KG, Rutten CL, Schuurhuis A, Knape JT, Kalkman CJ, et al. The effect of outpatient preoperative evaluation of hospital inpatients on cancellation of surgery and length of hospital stay. Anesth Analg. 2002;94: 644-9.

3. Cihoda JH, Alves JR, Fernandes LA, de Souza Neto EP, Cihoda JH. The analysis for the causes of surgical cancellations in a Brazilian university hospital. Care Manag J. 2015;16:41-7.

4. Association of Anaesthetists of Great Britain and Ireland. Pre-operative assessment and patient preparation the role of the anaesthetist. AAGBI Safety Guidelines. 2010.

5. Chang JH, Chen KW, Chen KB, Poon KS, Liu SK. Case review analysis of operating room decisions to cancel surgery. BMC Surg. 2014;14:47.

6. Fitzsimons MG, Dilley JD, Moser C, Walker JD. Analysis of 43 intraoperative cardiac surgery case cancellations. J Cardiothorac Vasc Anesth. 2016;30:19-22. 
7. Hussain AM, Khan FA. Anaesthetic reasons for cancellation of elective surgical inpatients on the day of surgery in a teaching hospital. J Pak Med Assoc. 2005;55:374-8.

8. Paschoal ML, Gatto MA. Rate of surgery cancellation at a university hospital and reasons for patients' absence from the planned surgery. Revista Latino Americana Enfermagem. 2006;14:48-53.

9. Hawes RH, Andrzejowski JC, Goodhart IM, Berthoud MC, Wiles MD. Factors influencing pre-operative assessment time. Anaesthesia. 2016;71:273-9.

10. Olson RP, Dhakal IB. Day of surgery cancellation rate after preoperative telephone nurse screening or comprehensive optimization visit. Perioper Med. 2015:4:12.

11. Gaucher S, Boutron I, Marchand-Maillet F, Baron G, Douard R, Béthoux JP, AMBUPROG Group Investigators. Assessment of a standardized preoperative telephone checklist designed to avoid late cancellation of ambulatory surgery: The AMBUPROG multicenter randomized controlled trial. PLoS One. 2016;11:e0147194.

\section{Submit your manuscript to a SpringerOpen ${ }^{\circ}$ journal and benefit from:}

- Convenient online submission

- Rigorous peer review

- Immediate publication on acceptance

- Open access: articles freely available online

- High visibility within the field

- Retaining the copyright to your article

Submit your next manuscript at $\boldsymbol{s p r i n g e r o p e n . c o m ~}$ 